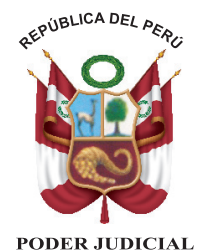

\title{
III CONGRESO NACIONAL \\ DE \\ MAGISTRADOS DEL PODER JUDICIAL
}

\section{DECLARACIÓN DE PIURA}

Los señores Presidentes de las diferentes Cortes Superiores de Justicia del país, suscriben la presente declaración correspondiente al Tercer Congreso Nacional de Magistrados del Poder Judicial, desarrollado en la cálida ciudad de Piura los días 18, 19 y 20 de noviembre de 2009, en los siguientes términos:

Primero: Proponer las acciones necesarias para modificar el texto constitucional a fin de derogar las normas vinculadas al proceso de ratificación judicial.

Segundo: Requerir se fortalezca el control disciplinario mediante la Oficina de Control de la Magistratura con reglas claras y objetivas, garantizando el debido proceso, sin afectar las decisiones jurisdiccionales, las cuales deben ser objeto de revisión únicamente por el órgano superior, en merito del principio constitucional de pluralidad de instancias; debiendo sancionarse las quejas maliciosas.

Tercero: Rechazar toda interferencia interna o externa sobre la actividad jurisdiccional.

Cuarto: Fortalecer la justicia de paz, incrementándose el apoyo logístico y de capacitación.

Quinto: Reconocer la existencia de un déficit en la infraestructura del Poder Judicial, siendo necesario declararla en emergencia con la finalidad de dictar medidas urgentes para la solución de dicho problema. 
Sexto: Presentar proyecto de ley que permita la implementación progresiva de las notificaciones electrónicas con carácter obligatorio, en todo el sistema judicial.

Sétimo: Racionalizar la carga procesal; así como los recursos humanos y logísticos en forma equitativa por cada órgano jurisdiccional, previo estudio de proyección del incremento de la misma.

Octavo: Implementar un programa nacional de capacitación del personal auxiliar; así como la asignación de bonificación extraordinaria de aquellos que laboran en zonas alejadas.

Noveno: Priorizar la tarea de control preventivo a fin de detectar las deficiencias en prácticas de trabajo judicial que potencialmente sean causa de actos de corrupción; y, especializar a los Jueces de Control a fin de dedicarlos exclusivamente a dicha función. Contar con un proceso disciplinario célere y que se publiquen las resoluciones absolutorias.

Décimo: Unificación de los diversos conceptos para que los magistrados cuenten con una remuneración única y que sirva para el cálculo de la compensación de tiempos de servicios y pensión. Se implementen las coberturas de pólizas de salud y de seguro de vida en caso de accidentes.

Décimo Primero: Aprobar la propuesta del nuevo despacho judicial para Juzgados Especializados y salas superiores, elaborado por la Comisión Nacional de Magistrados designados por el Consejo Ejecutivo del Poder Judicial; su implementación deberá responder a la realidad de cada Corte Superior de Justicia

Décimo Segundo: Conjugar esfuerzos para lograr el mismo porcentaje participativo de varones y mujeres en los órganos de gobierno, jurisdiccionales y administrativos del Poder Judicial.

Décimo Tercero: Apoyar la propuesta de derogatoria del artículo 47 inciso 6 de la Ley de la Carrera Judicial, así como la demanda de inconstitucionalidad interpuesta por la Fiscal de la Nación.

Décimo Cuarto: Reconocer póstumamente la trayectoria profesional del Doctor Florencio Mixán Mass.

Décimo Quinto: Expresar felicitación al señor Presidente del Poder Judicial, doctor Javier Villa Stein, por las gestiones para el otorgamiento de la bonificación por resultados a favor de los trabajadores de este Poder del Estado; y ratificarle nuestro total respaldo en las medidas adoptadas para el mejoramiento de servicio de justicia impulsando buenas prácticas en la gestión y administración de justicia.

Firmas 


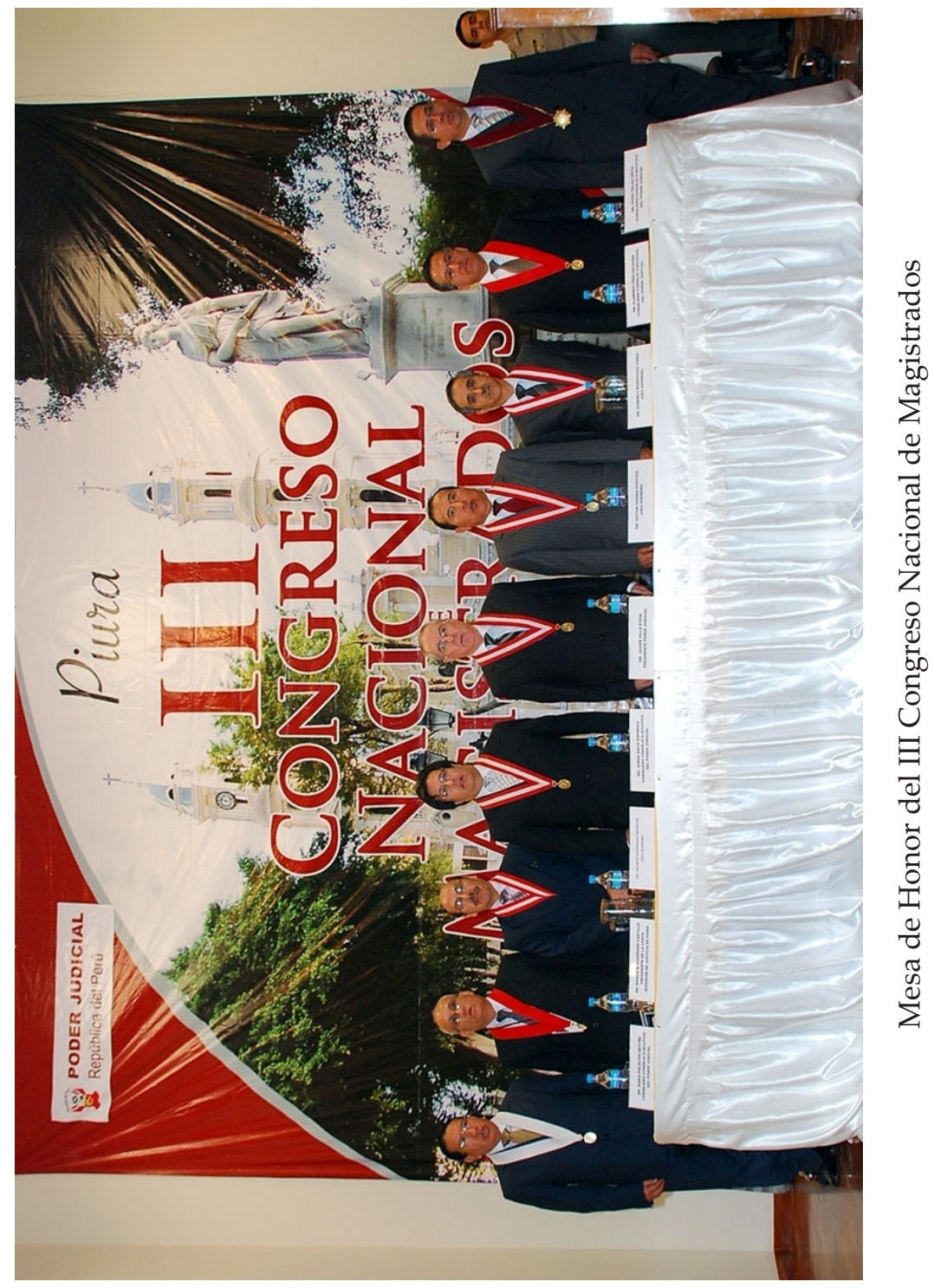





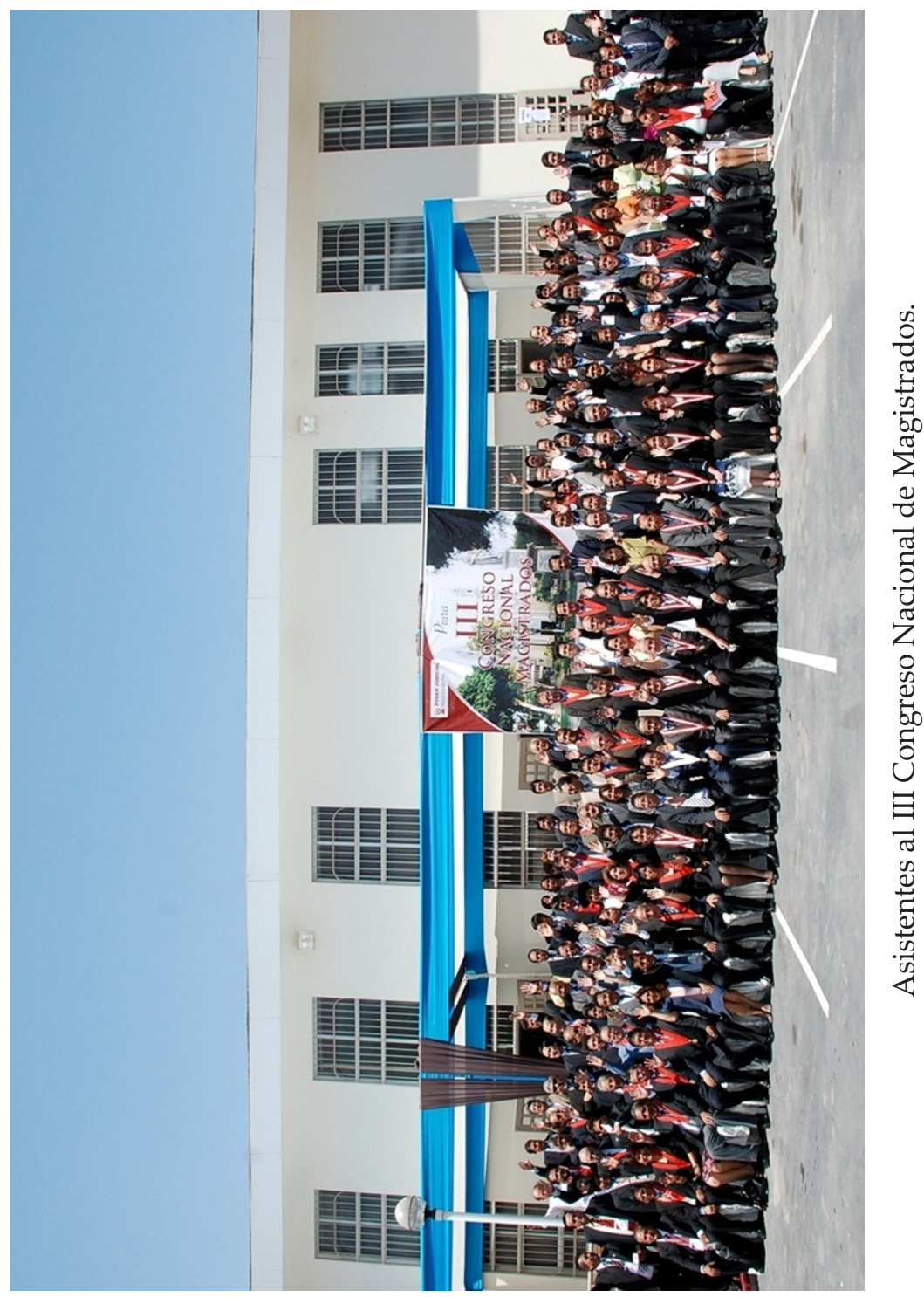

